\title{
Inguinal hernias in patients of 50 years and above. Pattern and outcome
}

\author{
Avaliação do tratamento da hérnia inguinal em pacientes com mais de 50 anos \\ de idade
}

Dr. Devalit Chowlek Shyami'; Dr. Amy Grace Rapsang ${ }^{2}$

\begin{abstract}
A B S S T R A C T
Objective: to evaluate a one year experience with inguinal hernia repair, in patients of > 50years, with respect to the type of inguinal hernia, type of surgery, postoperative complications and recurrence. Methods: a prospective descriptive study of patients $(n=57)>50$ years operated for inguinal hernia during a one year period. Tension-free meshplasty and herniorrhaphy, using 3"x6" polypropylene mesh and 2-0 polypropylene suture, were performed in elective and emergency surgery respectively. Follow-up visits were scheduled at six weeks, three and six months postoperatively. Results: the most representative age group was 61-70 years, and all patients were male. 52 (91.22\%) patients had unilateral inguinal hernias, while five $(8.77 \%)$ had bilateral hernias. In $50(87.71 \%)$ patients, the hernia was uncomplicated, while seven $(12.28 \%)$ patients presented with some complication such as obstruction or strangulation. Elective surgery was performed in $50(87.71 \%)$ patients while seven $(12.28 \%)$ patients were operated in emergency. Postoperatively, 50 (87.7\%) patients had uneventful recovery, while seven (12.28\%) patients developed some complications which were treated conservatively. Mean hospital stay was six days. One recurrence was observed and there was no peri/postoperative death. Conclusion: tension-free meshplasty and herniorrhaphy are safe, simple and applicable even in elderly patients after adequate preoperative assessment and optimization. Although associated with longer hospital stay, the mortality rate is nil and complication as well as recurrence rate is low. Hence, timely repair is necessary in elderly patients even in those with comorbid conditions.
\end{abstract}

Key words: Hernia. Hernia, inguinal. Herniorrhaphy. Surgical mesh. Postoperative complications.

\section{INTRODUCTION}

$\mathrm{H}^{\mathrm{n}}$ ernia is derived from the Latin word for rupture ${ }^{1}$. A hernia is defined as an abnormal protrusion of an organ or tissue through a defect in its surrounding walls. Although a hernia can occur at various sites of the body, these defects most commonly involve the abdominal wall, particularly the inguinal region?.

Hernia surgery is one of the earliest forms of surgery and various techniques of hernia repair have been described. The ideal treatment of inguinal hernia should be well defined and should be the least traumatic as regards to both the requested type of anesthesia and the operative technique, least expensive, least per-and postoperative morbidity, the chosen technique should also be the easiest to learn and perform and the positive results should be the most reproducible?
Tension free techniques for hernia repair has enjoyed widespread use for many years, with excellent results, few recurrences and little postoperative morbidity ${ }^{3}$. Earlier, nylon (a polyamide), was used as a mesh in inguinal hernia surgery, but the limitation faced was that polyamide degenerates over time. This led to the use of other synthetic materials, such as, polyester, polypropylene, expanded polytetrafluoroethylene (ePTFE) etc. The use of polypropylene mesh in hernia surgery has become increasingly popular. The use of synthetic mesh for achieving a tension free repair has resulted in a significant reduction in postoperative recurrences ${ }^{4}$. Polypropylene meshes have a mild reactivity upon implantation, in-growth, tensile strength which is retained for indefinite periods of time and a low susceptibility to mesh infection ${ }^{5}$, but, they can induce adhesion of viscera when placed intraperitoneally ${ }^{6}$. Polyesters also have flexibility, high tensile

Work attributed to: Guwahati Medical College, (Guwahati, India).

1. Assistant Professor, General Surgery North Eastern Indira Gandhi Regional Institute of Health and Medical Sciences; 2. Senior Resident, Anesthesiology, North Eastern Indira Gandhi Regional Institute of Health and Medical Sciences. 
strength and high resistance to stretching, but can cause fistula formation, hernia recurrence, postoperative infections and degradation in long-term implantation ${ }^{7,8}$. Expanded polytetrafluoroethylene (ePTFE), was introduced to hernia surgery by Sher et al. ${ }^{9}$; ePTFE has lower rates of adhesion formation than polypropylene ${ }^{10}$, but, infection of an ePTFE mesh may require removal of the mesh.

Risk factors that are useful in predicting complications in an adult patient with a groin hernia include old age, short duration, femoral hernia, and coexisting medical illness. Reluctance for surgery due to economical reasons coupled with a general fear for surgery is the main reason for an increasing number of elderly surgical patients in developing countries ${ }^{11}$.

Most of the elderly patients requiring surgery also have associated comorbidities. Reluctance for operation leads to complications at some stage and it has been pointed out in many studies that the mortality and morbidity increases many fold if such hernias are operated in the emergency setting in elderly patients ${ }^{11,12}$.

The present study evaluates the management of inguinal hernias in patients of 50 years and above, for to aid to explain this problem in this group of patients, with respect to the type of inguinal hernia, type of surgery, postoperative complications and recurrence.

\section{METHODS}

After approval by the Hospital Ethics Committee and written informed consent, 57 patients ( $>50 \mathrm{yrs}$ ) of either sex, diagnosed with inguinal hernia, were included in this prospective descriptive study.

Patients were admitted through casualty or outpatient department, in a one year study period. Patients who are $<50$ years or who refused surgery were excluded from the study.

Comorbidities were taken care of in elective as well as in emergency situations. The patients were operated after thorough clinical and laboratory evaluation. Patients who presented with complicated hernias were operated in an emergency setting after pre-requisite investigations and resuscitation.

The anesthesia employed was determined by anesthetist after assessment of the patients. All patients underwent inguinal hernia repair tension-free meshplasty or hernioplasty was performed for uncomplicated inguinal hernias and herniorrhaphy was performed for complicated inguinal hernias. In tension-free meshplasty, a 3 "x6" polypropylene mesh was used over the posterior abdominal wall, and in herniorrhaphy, a 2-0 polypropylene suture was used to approximate the conjoin tendon and the inguinal ligament in order to strengthen the weak posterior wall. Follow-up visits were scheduled for six weeks, three months and six months postoperatively. Manual workers were advised to start light work after six weeks. The variables studied included patient demographics (gender and age), type of inguinal hernia (direct or indirect, complicated or uncomplicated), associated co morbidities, type of surgery, type of anesthesia given, postoperative complications and recurrence.

\section{RESULTS}

Inguinal hernia repair was performed in 57 patients and all the patients were male. Patient demographics and clinical characteristics are given in table 1. Tension free meshplasty was performed in 47 patients with uncomplicated inguinal hernia and herniorrhaphy was performed in the remaining ten patients (out of the ten patients, seven were complicated hernias and three patients were too poor to afford a mesh, hence herniorraphy had to be done).

All patients were above 50 years of age, and the most representative age group was from 61-70 years, with 32 patients. The oldest patient was 82 years old. Direct hernia was seen in 30 patients (52.63\%) and indirect hernia was seen in 27 (47.36\%) patients. In 34 patients (59.64\%) the hernia was on the right side, in 18 patients $(31.57 \%)$ it was on the left side and in five patients (8.77\%), it was bilateral.

Amongst 57 patients of inguinal hernia, 50 were uncomplicated (45 unilateral and five bilateral) and seven patients presented as complicated inguinal hernia; and of the seven complicated cases, obstruction was present in three patients, strangulation were seen in three patients and Richter's hernia in one patient.

In this study it was observed that the incidence of inguinal hernia is highest amongst the group engaged in hard and strenuous manual work where most of them were cultivators. Pain was the most common presenting feature in this study (53 patients), and many of them have associated comorbidities (Table 2).

Elective surgery patients associated with comorbidities, were evaluated by the anesthetist in the preanesthetic clinic and anesthetic clearance was obtained and patients were optimized before the surgery was perform, whereas, emergency cases were optimized and hemodynamically settled before taking up for surgery.

Table 1 - Patient demographics and clinical characteristics.

\begin{tabular}{lc}
\hline Characteristics & Variable \\
\hline Age & $>50$ years \\
Number of patients & 57 \\
Gender $\quad$ Male & 57 \\
Emergent repairs & 0 \\
Elective repairs & 7 \\
Recurrent hernias & 50 \\
\hline
\end{tabular}


Table 2 - Associated co-morbidities.

\begin{tabular}{lcc}
\hline Comorbidities & Number & of \\
\hline Prostatic enlargements & 20 & Percentage \\
Pulmonary diseases & $17.54 \%$ & $35.08 \%$ \\
· Pulmonary Koch's & 1 & \\
- Chronic bronchitis & 6 & \\
- Bronchial asthma & 3 & $15.78 \%$ \\
Diabetes mellitus & 9 & \\
Cardiac diseases & $35.08 \%$ & \\
· Hypertension & 14 & \\
- Atrial fibrillation & 3 & \\
- Irregular heart beat & 1 & \\
- Left ventricular hypertrophy & 2 & \\
\hline
\end{tabular}

Tension free meshplasty or herniorrhaphy was then performed accordingly in all patients (Table 3). Ileal resection and end to end anastomosis was also carried out in three patients with strangulation. Table 4 shows the type of anesthesia given by the anesthetist for all the patients operated.

Postoperatively $50(87.7 \%)$ patients had uneventful recovery with no complications. In patients undergoing tension-free meshplasty, short term morbidity is represented by one postoperative urinary retention $(1.75 \%)$, one surgical site infection (superficial wound infection) (1.75\%) and two scrotal edema (3.5\%). Two patients with previous pulmonary disease, develop pulmonary complication (respiratory tract infection) (3.5\%).
In the herniorrhaphy group, there is only one surgical site infection (superficial wound infection) (1.75\%), which later on present as recurrence. There was no perioperative death and mortality rate was nil.

Most of the patients were discharged on the sixth day. Hospital stay ranged from 4-28 days, with a mean hospital stay of 12.5 days. Follow-up visits were scheduled for six weeks, three months and six months postoperatively. One recurrence was observed after nine months of operation. Initially on admission, this patient had prostatic enlargement and he presented to the emergency department with strangulation. The patient was taken up for surgery where herniorraphy, ileal resection and end to end anastomosis were done under general anesthesia.

Table 3 - Type of surgery performed.

\begin{tabular}{lcl}
\hline Type of Inguinal hernia & Number of patients & Surgery performed \\
\hline Uncomplicated unilateral inguinal hernia & 45 & $\begin{array}{l}\text { Tension free meshplasty (42 patients) using 3"x6" } \\
\text { polypropylene meshHerniorraphy (3 patients) using } \\
2-0 \text { polypropylene suture }\end{array}$ \\
Uncomplicated bilateral inguinal hernia & 5 & $\begin{array}{l}\text { Bilateral tension free meshplastyusing 3 " } \times 6 \text { " } \\
\text { polypropylene mesh } \\
\text { Complicated inguinal hernia* }\end{array}$ \\
Herniorraphy using 2-0 polypropylene suture
\end{tabular}

* Ileal resection and end to end anastomosis was also carried out in 3 patients with strangulation.

Table 4 - Type of anesthesia given.

\begin{tabular}{llcc}
\hline Type of Inguinal hernia & Type of Anesthesia given & Number of patients & Percentage \\
\hline Uncomplicated inguinal hernia & Spinal anesthesia & 39 & $64.91 \%$ \\
& Local anesthesia & 5 & $8.77 \%$ \\
& Epidural anesthesia & 3 & $5.26 \%$ \\
& Local anesthesia with sedation & 2 & $3.5 \%$ \\
& Sedation & 1 & $1.75 \%$ \\
Complicated inguinal hernia & General anesthesia & 0 & $0 \%$ \\
\hline
\end{tabular}


In the postoperative period, the patient developed wound infection which was managed conservatively and nine months later, he presented with recurrence. The long term follow-up of the rest of the patients did not show any persistent pain, groin and testicular hypoesthesia and no other recurrence has been found, neither sinus nor fistula formation.

\section{DISCUSSION}

Elective repair of inguinal hernias is a low risk procedure which can be safely performed under general/ regional/local anesthesia with few complications and low mortality ${ }^{13}$, and should be performed soon after diagnosis is made and following adequate preparation even in the extreme elderly ${ }^{14}$. The incidence of inguinal herniation is higher in the elderly aged $>65$ years ${ }^{15}$ and they also have concomitant medical problems which increase the risk of surgery, but even though morbidity in elderly is reported to be three times higher than in younger patients, age or comorbidity should not be a barrier to inguinal hernia repair $^{14}$.

The choice of the time in which to perform the operation is also important due to complications which may arise because of the necessity of urgent operations, also taking into account the possible health deterioration of elderly patients with comorbid conditions ${ }^{16}$. Risks evaluation must include the general condition of the patient and associated comorbid conditions. In our study, most of our patients have associated comorbidity (Table 2). One study ${ }^{16}$ on elderly patients with cardiovascular disease concluded that the type of open surgery (tension-free) used, has no relevance as to the results to be reached and has the same advantages which have been observed in elderly non cardiac risk patients, such as a faster functional recuperation as well as no significant percentage difference related to the early and late complications following the operation, but with longer hospital stay.

One of the most striking features of inguinal hernia is its sex distribution. The male to female ratio is $9: 1^{17}$. In our study, results were somewhat similar, in which $100 \%$ of the operations were on men. This is in line with other studies where inguinal hernia is more in men as compared to women. In a study by Primatesta et al. ${ }^{18}, 90 \%$ of operations were on men, and Dabbas et al. ${ }^{19}$, reported that inguinal hernia repairs were carried out in total almost 15 times more commonly in men than in women.

Inguinal hernias are also more common in the right sided (almost 55\%) ) $^{19}$. Our study also showed right predominance with $31.57 \%$ left sided, 59.64\% right sided repairs and $8.77 \%$ bilateral. A study by Dabbas et al. ${ }^{19}$ also shows a similar trend with $49 \%$ left and $51 \%$ right sided repairs.

In our study, it was observed that the incidence of inguinal hernia is highest amongst the group engaged in hard and strenuous manual work where most of them were cultivators. Literature suggested that although inguinal hernias appears to occur more frequently in heavy laborers, a history of sudden onset of pain after a specific lifting episode is unusual except in worker's compensation patients ${ }^{20}$.

The lifetime risk of inguinal hernia repair is high $-27 \%$ for men and $3 \%$ for women ${ }^{18}$. The mortality increases after emergency repairs ${ }^{18}$, hence elective repair should be considered as soon as diagnosis is made to prevent any adverse outcome. Mortality risks following elective hernia repair is low even in older age groups, but, it carries a substantial mortality risk if it is an emergency operation ${ }^{21}$. In a study by Nilsson et al. ${ }^{21}$, the mortality risk increases seven fold in an emergency operation as compared to an elective repair and 20 fold if bowel resection is undertaken. In our study, there was no mortality both in elective and emergency repair.

Few hernia relapses have been reported after primary repair of inguinal hernias. About $20 \%$ of groin hernia repairs are done due to recurrences ${ }^{22}$. In a study by Pavlidis et al. ${ }^{14}$, the recurrence rate after tension free technique for inguinal hernia repair was as low as $1.5 \%$. Gianetta et al. ${ }^{23}$ reported a low recurrence rate of $1.8 \%$, Liem et al..$^{24}$ reported $6 \%$ recurrence, Champault et al. ${ }^{25}$ reported 2\% recurrence and the MRC Laparoscopic Groin Hernia trial Group ${ }^{26}$ and Amid et al. ${ }^{3}$ reported as low as $0 \%$ recurrence rate after open repair of groin hernia surgeries. Our study is also consistent with these findings with a low recurrence rate of $1.75 \%$.

In a study by Shaikh et al..27, 90.7\% of the patients had uneventful recovery and $5 \%$ developed surgical site infection, while Amid et al. reported less than $2 \%$ wound infection ${ }^{3}$. Gianetta et al. ${ }^{23}$ reported $2.7 \%$ scrotal hematoma, $2 \%$ cord edema, $0.7 \%$ orchitis and $0.7 \%$ wound infection. In our study, $87.7 \%$ of patients have uneventful recovery. In both inguinal hernia repair techniques, $3.5 \%$ of the patients who already have some respiratory compromise pre-operatively, had postoperative respiratory tract infection. Surgical site infection and scrotal edema was seen in a total of 3.5\% patients and postoperative urinary retention was seen in $1.75 \%$ patients.

Chronic groin pain has been reported in many studies (Erhan et al..$^{28}$ reported $4-6 \%$ of patients having chronic pain after Lichtenstein and preperitoneal hernia repair and Phoolbalan et al. ${ }^{29}$ reported a $10 \%$ incidence of pain after inguinal herniorrhaphy). Several risk factors seems to play an important role in the development of chronic groin pain, such as surgeons experience, day care surgeries, intensity of immediate postoperative pain and degree of specialization ${ }^{28,29}$. One author quoted a $20 \%$ rate of nerve entrapment ${ }^{30}$ but studies rarely mentioned whether surgeons identified the Ilioinguinal nerve or lliohypogastric nerve during open dissection or not $^{31}$. In our study, there was no incidence of chronic 
groin pain, probably because the above risk factors were eliminated.

In our descriptive study, inguinal hernia repair "Tension-free meshplasty" and "Herniorrhaphy", proved to be convenient, economical and safe for elderly patients, with little post-operative complications and no mortality.

Several types of anesthesia techniques have been described for inguinal hernia repair. Local anesthesia is preferred over the other types of anesthesia ${ }^{16,32}$ even though hypotension and bradycardia have been reported ${ }^{33}$. Regional anesthesia techniques (spinalepidural) have a high risk of urinary retention ${ }^{16}$, and general anesthesia is associated with the need for full preoperative workup and longer postoperative recovery ${ }^{14}$ and hospital stay. In a study by Pavlidis et al. ${ }^{14}$ spinal was the type of anesthesia most frequently used in the elderly patients (38.5\%), followed by general anesthesia $(29.6 \%)$ and local anesthesia (16.3\%). They attributed the low percentage of use of local anesthesia to the higher incidence of larger hernias in elderly patients as well as the fear for increased intraoperative pain with subsequent disastrous hypotension. In our study, spinal was the type of anesthesia most frequently used (64.91\%), followed by general anesthesia (14.03\%), local anesthesia (12.28 $\%)$, epidural anesthesia (5.26\%) and sedation (3.5\%). General anesthesia was mainly employed for complicated hernias. Local anesthesia was not the technique of choice in our study since most of the elderly patients were uncooperative and were afraid of the possibility of feeling pain while injecting.

Another approach of hernia repair is the laparoscopic approach. Liem et al ${ }^{34}$ showed that laparoscopic repair have fewer recurrences and chronic inguinal pain as compared to the open technique, while others showed low recurrence with open tension free technique when compared to laparoscopic repair ${ }^{35}$. Even though laparoscopic repair has the advantages of less postoperative pain, shorter hospital stay and shorter convalescence as compared to the open technique ${ }^{3,35}$, it is considered as a complimentary choice and not as an alternative to open surgery in elderly patients ${ }^{2}$. In elderly patients with comorbid conditions, the laparoscopic approach, which is only limitedly applied in the surgical treatment of hernia, has to be unquestionably eliminated, as it would imply the need of resorting to general anaesthesia. The disadvantages of the laparoscopic approach is the higher cost of laparoscopy and some authors underline that laparoscopy is more difficult to perform and to learn than open surgery ${ }^{36}$ and in elderly patients, the need to resort to general anesthesia which is mandatory in laparoscopic surgery. The fact that elderly patients do not have a necessity for a rapid renewal of hard work or sport, therefore, another advantage of laparoscopy is lost².

In our study, we did the open conventional technique of hernia repair and did not consider laparoscopic approach because our patients' study age group $>50$ years and hence many of them would be expected to have associated comorbid conditions and moreover the laparoscopic unit in our Institute is not yet well developed at the time of conductance of this study. The results of our study showed that despite the presence of comorbidities and long hospital stay, there was no mortality, very few complications and low recurrence rate.

In conclusion, we can state that based on our results and observations, tension-free meshplasty and herniorrhaphy are safe, simple and applicable even in elderly patients after adequate pre-operative assessment and optimization. Although associated with longer hospital stay, the mortality rate is nil and complication as well as recurrence rate is low. Hence, timely repair is necessary in elderly patients even in those with comorbid conditions.

\section{R E S U M O}

Objetivo: avaliar a experiência de um ano com a correção de hérnia inguinal, em pacientes > 50 anos de idade, em relação ao tipo de hérnia inguinal, tipo de operação, complicações pós-operatórias e recorrências. Métodos: estudo descritivo prospectivo de pacientes $(n=57)>50$ anos de idade operados de hérnia inguinal durante um período de um ano. Herniorrafia com tela livre de tensão, utilizando a tela de polipropileno $3 \times 6^{\prime \prime}$, e herniorrafia com suturas, utilizando fio de polipropileno 2-0, foram realizadas em operações eletivas e de emergência. Acompanhamento de visitas foram agendadas em seis semanas, três e seis meses no pósoperatório. Resultados: o grupo etário mais representativo foi 61-70 anos, e todos os pacientes eram do sexo masculino. Cinquenta e dois pacientes (91,22\%) apresentavam hérnia inguinal unilateral, enquanto cinco (8,77\%) tinham hérnias bilaterais. Em 50 pacientes $(87,71 \%)$, as hérnias eram sem complicações, enquanto sete $(12,28 \%)$ pacientes apresentavam complicações, tais como obstrução ou estrangulamento. Operações eletivas foram realizadas em 50 pacientes (87,71\%), enquanto sete (12,28\%) pacientes foram operados em situações de emergência. No período pós-operatório, 50 (87,7\%) pacientes tiveram recuperação sem intercorrências, enquanto sete (12,28\%) pacientes desenvolveram complicações que foram tratadas conservadoramente. A média de permanência hospitalar foi seis dias. Observou-se um caso de recorrência e não houve nenhuma morte per/pós-operatória. Conclusão: Herniorrafia com tela livre de tensão e herniorrafia com suturas são seguras, simples e aplicáveis, mesmo em pacientes mais idosos. As recorrências e as complicações, embora associadas a uma maior permanência hospitalar, são eventos de baixa incidência e a taxa de mortalidade foi zero.

Descritores: Hérnia. Hérnia Inguinal. Herniorrafia. Telas cirúrgicas. Complicações pós-operatórias. 


\section{REFERENCES}

1. Malangoni MA, Gagliardi RJ. Hernias. In: Townsend CM, Beauchamp RD, Evers BM, Mattox KL, editors. Sabiston's Textbook of Surgery. 17th edition. Philadelphia: Elsevier-Saunders; 2004. p.1199-218.

2. Roseano M, Ressetta G, Pozzetto B, Babich F, de Manzini N. The treatment of inguinal hernia in the elderly: open technique or laparoscopic approach? Acta Biomed. 2005;76 Suppl 1:52-5.

3. Amid PK, Shulman AG, Lichtenstein IL. Open "tension-free" repair of inguinal hernias: the Lichtenstein technique. Eur J Surg. 1996;162(6):447-53

4. Amid PK, Lichtenstein IL, Shulman AG, Hakakha M. Biomaterials for "tension-free" hernioplasties and principles of their applications. Minerva Chir. 1995;50(9):821-6.

5. Morris-Stiff GJ, Hughes LE. The outcomes of nonabsorbable mesh placed within the abdominal cavity: literature review and clinical experience. J Am Coll Surg. 1998;186(3):352-67.

6. Voyles CR, Richardson JD, Bland KI, Tobin GR, Flint LM, Polk HC Jr. Emergency abdominal wall reconstruction with polypropylene mesh: short-term benefits versus long-term complications. Ann Surg. 1981;194(2):219-23.

7. Leber GE, Garb JL, Alexander Al, Reed WP. Long-term complications associated with prosthetic repair of incisional hernias. Arch Surg. 1998;133(4):378-82

8. Klosterhalfen B, Klinge U, Hermanns B, Schumpelick V. Pathology of traditional surgical nets for hernia repair after long-term implantation in humans. Chirurg. 2000;71(1):43-51.

9. Sher W, Pollack D, Paulides CA, Matsumoto T. Repair of abdominal wall defects: Gore-Tex vs. Marlex graft. Am Surg. 1980;46(11):618-23.

10. Brown GL, Richardson JD, Malangoni MA, Tobin GR, Ackerman D, Polk HC Jr. Comparison of prosthetic materials for abdominal wall reconstruction in the presence of contamination and infection. Ann Surg. 1985;201(6):705-11.

11. Malik AM, Khan A, Talpur KA, Laghari AA. Factors influencing morbidity and mortality in elderly population undergoing inguinal hernia surgery. J Pak Med Assoc. 2010;60(1):45-7.

12. Mansouri M, Ekjam S, Hudairi A, Sannussi Ol, Fakheri A. Emergency abdominal surgery in Libyan elderly patients. Sci Med J. 2005;17(3):57-65.

13. Behnia R, Hashemi F, Stryker SJ, Ujiki GT, Poticha SM. A comparison of general versus local anesthesia during inguinal herniorrhaphy. Surg Gynecol Obstet. 1992;174(4):277-80.

14. Pavlidis TE, Symeonidis NG, Rafailidis SF, Psarras K, Ballas KD, Baltatzis $\mathrm{ME}$, et al. Tension-free by mesh-plug technique for inguinal hernia repair in elderly patients. Scand J Surg. 2010:99(3):137-41.

15. Sanjay P, Woodward A. Inguinal hernia repair: local or general anesthesia? Ann R Coll Surg Engl. 2007;89(5):497-503.

16. Frazzetta M, Di Gesù G. Inguinal hernia surgery performed on elderly cardiopath patients. Acta Biomed. 2005;76; Suppl 1:42-5.

17. Bax T, Sheppard BC, Crass RA. Surgical options in the management of groin hernias. Am Fam Physician. 1999;59(1):143-56. Correct and republished in: Am Fam Physician. 1999;59(4):893-906.

18. Primatesta P, Goldacre MJ. Inguinal hernia repair: incidence of elective and emergency surgery, readmission and mortality. Int J Epidemiol. 1996;25(4):835-9.

19. Dabbas N, Adams K, Pearson K, Royle G. Frequency of abdominal wall hernias: is classical teaching out of date? JRSM Short Rep. 2011;2(1):5

20. Fitzgibbons RJ, Filippi CJ, Quinn TH. Inguinal hernias. In: Brunicardi FC, Anderson DK, Billiar TR, Dunn DL, Hunter JG, editors. Shwartz's Principles of Surgery. 8th edition. New York: McGraw Hill; 2005. p.1353-1394
21. Nilsson H, Stylianidis G, Haapamäki M, Nilsson E, Nordin P. Mortality after groin hernia surgery. Ann Surg. 2007;245(4):656-60.

22. Paajanen $H$, Varjo R. Ten-year audit of Lichtenstein hernioplasty under local anesthesia performed by surgical residents. BMC Surg. 2010:10:24.

23. Gianetta E, Cuneo S, Vitale B, Camerini G, Marini P, Stella M. Anterior tension-free repair of recurrent inguinal hernia under local anesthesia: a 7-year experience in a teaching hospital. Ann Surg. 2000:231(1):132-6.

24. Liem MS, van der Graaf Y, van Steensel CJ, Boelhouwer RU, Clevers GJ, Meijer WS, et al. Comparison of conventional anterior surgery and laparoscopic surgery for inguinal-hernia repair. N Engl J Med. 1997:336(22):1541-7.

25. Champault GG, Rizk N, Catheline JM, Turner R, Boutelier P. Inguinal hernia repair: totally preperitoneal laparoscopic approach versus Stoppa operation: randomized trial of 100 cases. Surg Laparosc Endosc. 1997;7(6):445-50.

26. Laparoscopic versus open repair of groin hernia: a randomised comparison. The MRC Laparoscopic Groin Hernia Trial Group. Lancet. 1999;354(9174):185-90.

27. Shaikh MS, Abro AA, Naz S, Shaikh SA, Shaikh AG, Seelro R, et al Outcomes of open mesh hernia repair: five year's experience at Chandka Medical College Hospital Larkana. JLUMHS 2009;8(3):205-9

28. Erhan $Y$, Erhan E, Aydede H, Mercan M, Tok D. Chronic pain after Lichtenstein and preperitoneal (posterior) hernia repair. Can J Surg. 2008;51(5):383-7.

29. Poobalan AS, Bruce J, Smith WC, King PM, Krukowski ZH, Chambers WA. A review of chronic pain after inguinal herniorrhaphy. Clin J Pain. 2003;19(1):48-54.

30. Stephenson BM. Complications of open groin hernia repairs. Surg Clin North Am. 2003;83(5):1255-1278

31. Grunwald LJ, Schwaitzberg SD, Rattner DW, Jones DB. Is laparoscopic inguinal hernia repair an operation of the past? J Am Coll Surg. 2005;200(4):616-20.

32. Nehme AE. Groin hernias in elderly patients. Management and prognosis. Am J Surg. 1983;146)2):257-60.

33. Gianetta E, de Cian F, Cuneo S, Friedman D, Vitale B, Marinari G, et al. Hernia repair in elderly patients. Br J Surg. 1997;84(7):983-

34. Liem MS, van Duyn EB, van der Graff $Y$, van Vroonhoven TJ Coala Trial Group. Recurrences after conventional anterior and laparoscopic inguinal hernia repair: a randomized comparison. Ann Surg. 2003;237(1)136-41.

35. Eklund AS, Montgomery AK, Rasmussen IC, Sandbue RP, Bergkvist LA, Rudberg CR. Low recurrence rate after laparoscopic (TEP) and open (Lichtenstein) inguinal hernia repair: a randomized multicenter trial with 5-year follow-up. Ann Surg. 2009;249(1):338

36. Papachristou EA, Mitselou MF, Finokaliotis ND. Surgical outcome and hospital cost analyses of laparoscopic and open tension-free hernia repair. Hernia. 2002;6(2):68-72.

Recebido em 05/10/2012

Aceito para publicação em 03/11/2012

Conflito de interesse: nenhum

Fonte de financiamento: nenhuma

\section{Como citar este artigo:}

Shyam DC, Rapsang AG. Inguinal hérnias in patients of 50 years and above. Pattern and outcome. Rev Col Bras Cir. [periódico na Internet] 2013;40(5). Disponível em URL: http://www.scielo.br/rcbc

\section{Endereço para correspondência:}

Dr. Devajit Chowlek Shyam

E-mail devajit_cs@yahoo.com 